\title{
Dilemas de la reproducción asistida
}

\author{
Dilemmas in assisted reproduction
}

${ }^{1}$ Unidad de Medicina Reproductiva, Clínica Las Condes. Lo Fontecilla 441, Santiago, Chile.

\begin{abstract}
Modern reproductive technologies, particularly in vitro fertilization (IVF) and gamete intrafallopian transfer (GIFT), have made possible the establishment of new families through the birth of hundreds of thousands of children worldwide. Meanwhile, these technologies have compelled men to face the possibility of intervening at the very origins of their own biological existence, hence creating doubts and questions beyond the domain of medical science. Society is now asking itself whether all that is scientifically and technically possible is necessarily beneficial to mankind. The answer to this question is not to be found in biological science alone, but instead requires multidisciplinary reflection including all forms of knowledge: philosophical, bioethical, and religious, all contributing to the unavoidable adventure that we are endowed with in the search for a better life.
\end{abstract}

Key words Reproduction; Reproduction Techniques; Fertilization in Vitro; Reproductive Medicine

Resumen La Fecundación In Vitro (FIV) y la Transferencia de Gametos a la Trompa de Falopio (GIFT) han hecho posible el nacimiento de cientos de miles de niños. Estas tecnologías han puesto al hombre frente a frente a la posibilidad de intervenir en los inicios de su propia existencia. La pregunta es si aquello que es científica y técnicamente factible es bueno para el hombre. La respuesta requiere de una reflexión multidisciplinaria. La filosofía, la bioética y las distintas corrientes religiosas tienen un grano de arena que aportar a este gran desafío.

Palabras clave Reproducción; Técnicas de Reproducción; Fecundación in Vitro; Salud Reproductiva 


\section{Introducción}

El desarrollo científico y tecnológico es un producto genuino de la naturaleza humana. El hombre, dotado de una inteligencia superior al resto de los habitantes del planeta, se ve permanentemente afectado por un llamado que nace de su interior y que lo obliga a descubrir, a aventurarse más allá de los límites que percibe a través de sus sentidos. Es esta fuerza aventurera y la curiosidad lo que motivó a nuestra especie a migrar y poblar las más vastas geografías, más allá de las necesidades alimentarias y reproductivas que movilizan a la mayor parte de los mamíferos. Esta fuerza aventurera también moviliza al hombre a descubrir los misterios de su propia existencia así como los del universo entero. De esta manera, la ciencia nace con el hombre como herramienta insustituible en el proceso de develar, de poner al conocimiento de todos, la maravilla de nuestra naturaleza.

La ciencia médica, desde tiempos inmemoriales, ha contribuido a reemplazar mitos y leyendas por explicaciones al alcance de la razón, poniendo de esta manera al hombre como el principal protagonista de su propio destino. La generación de la vida así como el advenimiento de la muerte ya no pueden tan sólo entenderse como un mandato divino unidireccional. A la mujer infertil, hoy la ciencia le permite parir y, al moribundo, hoy la ciencia le permite vivir. La ciencia y la tecnología modernas hicieron a algunos escépticos de una existencia divina. Para otros, la acción divina persiste, siendo el hombre, con su inteligencia y creciente sabiduría, una expresión más de la presencia de un ordenador superior.

El hombre es probablemente el único ser con conciencia de poseer una existencia que está limitada en el tiempo, el único ser con conciencia de muerte. Los humanos son probablemente los únicos con capacidad de entender que su caminar por este mundo se da en un plano existencial que lo precede y que lo seguirá por tiempos indefinidos, es decir, que su plano existencial forma parte de otro mucho mas amplio e inmutable.

De maneras muy variadas, el hombre tiene conciencia que su única posibilidad de proyectarse mas allá de su propia realidad es a través de la reproducción. Esta característica propia de todos los seres vivos adquiere en el hombre especial importancia desde el instante en que éste toma conciencia de ser un participante activo en el proceso generativo de la vida humana. La madre tierra o la madre mar pueden continuar siendo dos grandes madres, pero desde hace ya muchos años el hombre se reconoce a si mismo como el agente principal en la evolución de su propia especie. Así nace su preocupación por la fecundidad y por concentrar parte de sus esfuerzos científicos en estudiar esa materia.

Desde que P. Steptoe y R. Edwards, en 1978, lograron el primer embarazo con técnicas de fertilización in vitro y transferencia de conceptus (embriones) al útero (FIV/TE), la comunidad científica se vio conmovida por la posibilidad de intervenir efectivamente en el proceso reproductivo humano. Miles de parejas infértiles, que hasta ese entonces se encontraban imposibilitadas de tener hijos, recurrieron a estos procedimientos como un camino real y eficiente hacia la paternidad. Una vez más, la ciencia ponía una nueva tecnología al servicio de la humanidad. En esta oportunidad sin embargo, el descubrimiento científico dejó rápidamente de pertenecer a los científicos, pasando al dominio público. Las personas, por primera vez, tuvieron acceso a ser actores conscientes de los procesos biológicos conque se ponía en marcha su existencia material y naturalmente ello concitó la concurrencia de las más variadas formas del saber. Así, las diferentes corrientes filosóficas, religiosas, biológicas y legales han intervenido con justa razón en el debate y en la reflexión sobre los efectos éticos y legales que ese nuevo descubrimiento aportaba en la comunidad. Comunidad que finalmente se ha visto y se verá en un futuro afectada por una avalancha de nuevos descubrimientos que el hombre se ha dado, al abrir la puerta que lleva a la irrenunciable aventura de descubrir la maravilla de nuestra existencia.

\section{Enseñanzas de la biología del desarrollo pre-implantacional}

\section{Descripción}

Durante el proceso reproductivo que ocurre en forma espontánea, los espermatozoides dejados en la vagina luego del coito migran a través del cuello uterino hacia el interior del útero. De allí continuan su viaje hacia las trompas de Falopio. Una de ellas se constituirá en el escenario final para el encuentro con el gameto femenino, el óvulo. Durante su recorrido por el tracto genital femenino, el espermatozoide experimenta cambios estructurales y funcionales que le permitirán fusionar sus membranas con las del óvulo y penetrarlo. El óvulo, por su parte, una vez liberado del 
ovario, completa su maduración somática y germinativa, exponiéndose así a ser fecundado. El óvulo ha completado su maduración cuando sus dos "sets" de cromosomas se han reducido, durante la meiosis, a sólo uno. Al ingresar el espermatozoide a su interior, el óvulo estimula al gameto masculino a entregar su contenido cromosómico, poniendo en marcha la constitución de un nuevo individuo. Aproximadamente 12 horas depués de la penetración espermática, pueden distinguirse en el interior del ovocito dos estructuras llamadas pronúcleos que contienen los cromosomas paternos y maternos aún separados y encapsulados. Esta etapa del desarrollo se llama Cigoto. La fecundación se completa cuando, habiéndose fundido los cromosomas masculinos y femeninos, y habiéndose intercambiado información entre ambos, se inicia la primera división celular de un nuevo individuo. Jamás visto antes y que jamás será replicado, a no ser que ocurra posteriormente una división gemelar. Desde la fecundación y por los próximos tres días, el ahora llamado conceptus en división (etapa del desarrollo que se extiende desde la primera división celular hasta el día catorce a diecisiete del desarrollo) navega por el fluido tubárico llegando a la cavidad uterina entre el tercer y cuarto día. A pesar de lo avanzado del desarrollo, el conceptus no tomará contacto directo con tejidos maternos hasta iniciada la implantación, proceso que se inicia entre el quinto y sexto día de la fecundación.

En la etapa de conceptus, las sucesivas multiplicaciones celulares no constituyen especialización celular. Es decir, cada célula es igual a la siguiente, de tal manera que a un conceptus se le pueden extraer más de una célula sin que éste se vea afectado en funciones presentes o futuras. El conceptus tiene una sorprendente capacidad regeneradora que le permite sobreponerse con eficiencia a numerosas situaciones de estrés. Siendo todas las células del conceptus iguales, los diecisiete días de desarrollo marcan el último instante en que es posible la gemelación. En la mórula (conceptus de ocho o más células) y posteriormente en el blastocisto puede distinguirse una masa celular interna que dará origen al embrión propiamente tal y que no constituye más de un $10 \%$ de la totalidad de las células. El resto dará origen a la placenta y a otros anexos embrionarios. Si la masa celular interna es mayor que lo habitual, ésta puede dividirse en dos, dando orígen a gemelos idénticos. En términos estrictos, la biología del desarrollo nos habla de embrión desde el día 17 de la fecundación, en que aparece la hendidura neural que marca el inicio de especialización celular.

\section{Comentarios}

En general, las normativas legales, así como los conceptos filosóficos que las sustentan, intentan regular la naturaleza civil, las obligaciones y privilegios de las personas nacidas y las que están por nacer, de ahí que uno de los temas centrales en cualquier discusión se refiere al origen de la persona.

En la teología confuciana, se es persona cuando se nace y se deja de serlo con la muerte. En la mayor parte del mundo occidental, sin embargo, se sustenta la hipótesis que se es persona antes del nacimiento y sería difícil demostrar que una persona proviene de un algo que no es persona. De hecho, la posibilidad real de sobrevivir de recién nacidos de tan sólo siete meses de gestación obliga a pensar que se es persona desde antes de la fecha esperada para el nacimiento. En esta línea de pensamiento, parecería imprescindible definir desde cuando se es persona. Si esta pregunta se la hace a un embriólogo, éste, con la autoridad propia de su conocimiento, podrá contestar que la biología del desarrollo no define persona, sólo define estados dinámicos del desarrollo y que el concepto de persona debe mejor preguntársele a un filósofo. Éste, sin embargo, solicitará mayor información del biólogo y así sucesivamente, como viajando en círculos por un camino sin fin. Frente a la pregunta de cuando se es persona, el gran mufti de Jerusalén responde, con toda la autoridad que deriva de su conocimiento, que desde el día 160 de existencia. Si la misma pregunta se la hace a un católico, éste responderá con igual certeza que se es persona desde el momento de la concepción.

Cada persona, desde una perspectiva ontológica, es única y unitaria, es decir, la unidad de materia y espíritu le es propia a ella y sólo a ella. Desde esa perspectiva, no se puede ser persona antes del día 17 de desarrollo ya que, si en algún momento previo a esta etapa ocurre la división de la masa celular interna y se forman gemelos, el concepto de unitarismo se pierde, sin saber el alma a cual de las dos materias seguir. Por otra parte, es de común entendimiento que, cuando una persona tiene un electroencefalograma plano, sin actividad eléctrica, deja de ser persona viva. Esta es la base para las leyes de trasplantes. Si uno aplicase el mismo principio para demarcar los inicios, sólo podríamos hablar de persona desde la semana cuarta a octava de desarrollo, o sea, el mo- 
mento en que aparece por primera vez actividad eléctrica cerebral en el embrión.

Cada vez que se desea demarcar los inicios de una persona, se utiliza un juicio valorativo que lleva implícito que la etapa previa al supuesto inicio es menos importante o tiene menor trascendencia que la etapa siguiente. El uso de juicios valorativos es el que ha llevado a la legalización del aborto, cuyo sustento filosófico radica en que el derecho individual que tiene una persona nacida es mayor que el derecho del que está por nacer. Utilizar un juicio de esa naturaleza podría implicar que el derecho de una persona normal es superior al de un idiota o que el de un adulto es mayor que el de un niño. Cuando se utilizan juicios de valor para referirse a instantes transitorios del desarrollo de un indivíduo, se corre el riesgo de no saber donde están los límites e incurrir en atrocidades conceptuales. Cualquier estado del desarrollo de un indivíduo requiere, para su existencia, de una etapa previa de la cual no puede prescindir. No se puede llegar a adulto sin ser niño y no se puede ser niño sin ser embrión y así sucesivamente hasta la etapa de un cigoto unicelular. Si cada etapa del desarrollo se valora por lo que ésta representa, independientemente de si se expresará o no la etapa inmediatamente posterior, entonces, más importante que el ser es estar en el camino al ser. Así, más importante que definir desde cuando se es persona es definir y respetar el camino a ser persona. Como éste es un camino lleno de transformaciones, nunca se está seguro que se ha expresado la totalidad de ese indivíduo hasta que éste no ha llegado al final de su caminar, que sólo ocurre con la muerte.

La aplicación práctica del principio antes enunciado es que, creyendo en él, no pueden desecharse de la especie humana (persona = individuo de la especie humana), por más pequeños e insignificantes que parezcan ya que son en si mismo seres perfectos y tienen la potencialidad de llegar a ser uno más en nuestra especie, con caminos que les son propios y, respecto de los cuales, nadie puede sentir el derecho a interrumpir.

Las reflexiones en torno a los inicios de una persona adquieren especial interés frente a áreas de la tecnología reproductiva que tienen que ver con la criopreservación de conceptus en desarrollo, la investigación en conceptus y el diagnóstico genético pre implantacional.

\section{Criopreservación de conceptus}

El desarrollo de la criobiología ha permitido conservar a temperaturas de $-160^{\circ} \mathrm{C}$ concepti humanos en estado de dos y cuatro células, para su transferencia diferida en el tiempo en sus futuras madres.

Cuando a una mujer se le estimula la ovulación para FIV/TE, habitualmente se recuperan de sus ovarios una cantidad mayor de óvulos de los que pueden fecundarse para su transferencia inmediata sin que signifique un riesgo desproporcionado de multigestación. Los óvulos remanentes pueden desecharse o pueden donarse a otras mujeres, si la pareja así lo desea. Sin embargo, en aquellos centros que poseen tecnología de criopreservación, las parejas pueden acceder a fecundar la totalidad de los óvulos aspirados, transferir un número reducido de los concepti desarrollados y criopreservar el resto para ser transferidos en el futuro. El beneficio más evidentes de esta tecnología es permitir que un ciclo de estimulación y aspiración pueda derivar en varios intentos gestacionales. Ello acarrea una significativa disminución en las tasas de multigestación, ya que cada ciclo de estimulación puede significar dos o tres intentos de transferencia con un número menor de concepti, con un consiguiente ahorro en lo económico físico y emocional.

Las parejas se ven enfrentadas a reflexiones que tienen que ver con dos situaciones. La primera dice relación con el concepto de persona potencial representado en un conceptus de cuatro células y, por lo tanto, con el daño potencial al que se vería enfrentado un indivíduo sometido a congelación y descongelación. La ciencia médica entrega tasas de sobrevida luego de ciclos de congelación y descongelación que fluctúan entre un 40 a 100\% de los concepti criopreservados. La pregunta siguiente es si la muerte de algunos fue consecuencia de la criopreservación o si esta tecnología no ha hecho otra cosa que seleccionar a los más aptos, siendo los que sobreviven los mismos que hubieran alcanzado estados mayores de desarrollo aún sin haberse expuestos a la congelación. A pesar que aún no es posible contestar esta interrogante con certeza, la información relativa a desarrollo in vitro e in vivo de concepti humanos hace pensar que la pasada por el frío no elimina concepti normales, sino aquellos que de ningún modo habrían logrado estados mayores de desarrollo.

La segunda situación que merece reflexión tiene que ver con un concepto de tiempo. Un conceptus criopreservado es el único miembro 
de una determinada familia que queda detenido en el tiempo mientras el resto de los miembros continúan sus evoluciones naturales, sometidos a los cambios propios del tiempo. No se tiene conocimiento de como evolucionan las percepciones de los progenitores respecto de su decendencia que permanece detenida en el tiempo. Si al comienzo parecen hijos verdaderos y luego, con el tiempo, pasan a ser tan sólo células o, por el contrario, en la medida que pasa el tiempo, las cuatro células adquieren forma humana en la imaginación de sus potenciales padres futuros. Aparte del efecto impredecible del tiempo, estas interrogantes se verán afectadas por la presencia o no de hijos nacidos como consecuencia de la transferencia de concepti frescos, lo que dilatará aún más la transferencia de los criopreservados.

Cuando las parejas se ven enfrentadas a decidir sobre criopreservación, no tienen todos los elementos necesarios para hacer un juicio que se sustente en el tiempo, ya que el equipo profesional tampoco los tiene. No cabe la menor duda que muchas parejas se han beneficiado con la criopreservación, pero también es cierto que el número de concepti criopreservados aumenta en cantidades alarmantes, sobretodo a expensas de nuevos individuos cuyos progenitores prefieren no transferir.

Desde la perspectiva del conceptus en desarrollo, es razonable preguntarse que efecto puede tener sobre ese minúsculo individuo el detener sus ciclos de desarrollo. Si la individualidad se entiende como la interacción entre una determinada materia y su entorno, cualquier cambio en el entorno afecta al individuo de una manera que es particular a él. Así, detener el reloj de tiempo que se puso en marcha con la fecundación podría constituir una arbitrariedad cuyos efectos no estamos capacitados para entender. Diferente es la situación que se genera al criopreservar cigotos (previo a la singamia), ya que en ese estado de desarrollo aún no se ha constituído un nuevo individuo.

En las políticas de criopreservación deben buscarse puntos de equilibrio entre las evidentes ventajas en términos de eficiencia terapéutica, por una parte, y los potenciales problemas sicosociales a los que se pueden ver enfrentados los progenitores, equipos de salud y la comunidad entera que, de una u otra manera, se verán obligados a reflexionar sobre los inicios y el valor de sus propias existencias.

\section{Diagnóstico genético pre-implantacional}

Como se dijo anteriormente, el conceptus posee una capacidad regeneradora asombrosa; por ello, se pueden extraer una o más células del conjunto total sin alterar el devenir posterior. Ello permite realizar estudios e incluso efectuar modificaciones frente a enfermedades genéticas heredadas.

En el entendido que el proceso de obtener células con fines diagnósticos no altere el devenir del conceptus en desarrollo, no existen mayores controversias éticas. El problema se plantea frente a la decisión de transferir concepti que tienen, por ejemplo, trisomía del cromosoma 21 (llamado comúnmente mongolismo) u otra anomalía cromosómica compatible con la vida extra uterina. La diferencia que genera esta situación respecto de una mujer embarazada con un embrión en el que se diagnostica una trisomía 21 está en la doble dependencia del concepti que aún no ha sido transferido. En este caso, la transferencia depende tanto de la decisión de su futura madre como del equipo profesional que le provee transitoriamente el sustento vital. Cuando el diagnóstico se efectúa en la mujer ya embarazada, es ella y sólo ella quien toma la decisión de continuar o interrumpir la gestación. Decisión que finalmente se aplica en su interior.

La investigación en concepti es aceptada legalmente en el Reino Unido, en los Estados Unidos y en otros países. Nuevamente aquí la problemática central está en la idea que se tenga de persona o persona potencial respecto de un conceptus en división. Si a este se le confiere un estatus propio, deben regir para el las normativas propias de las investigaciones en personas menores de edad. Si así fuera, aún con el consentimiento de los progenitores, no existiría autoridad suficiente para permitir investigaciones que significasen un daño vital al individuo. Por el contrario, si en la etapa de conceptus no se reconocen características de persona potencial, la investigación en esta etapa de la vida no requiere más consentimiento que el otorgado por sus progenitores. Independientemente del devenir del individuo o sujeto de investigación.

Si se sustenta la hipótesis inicial respecto del valor prioritario del camino a ser persona por sobre el valor de cada estado en particular, entonces, aquello que debe ser preservado por sobre todo es el valor del individuo, desde que es tal y por sobre cualquier otra consideración, incluso la expresada por sus progenitores. 


\section{Donación y adopción de gametos}

\section{Descripción}

La donación de gametos se aplica en parejas heterosexuales infértiles en que uno o ambos miembros no posee células reproductivas. La carencia de espermatozoides en el hombre puede ser consecuencia de fallas en el estímulo hipofisiario en cuyo caso es posible estimular hormonalmente la gametogénesis. En aquellos casos en que la azoospermia es debida a obstrucciones de los conductos de salida, llamados epidídimo y conducto deferente, la tecnología reproductiva moderna ha desarrollado la micromanipulación o fecundación asistida que hace posible introducir mecánicamente un espermatozoide al interior del óvulo. Por sorprendente que parezca, el espermatozoide se comporta como un simple virus, entrega su contenido cromosómico siguiendo órdenes que provienen del óvulo y, así, el proceso reproductivo sigue su camino inmutable. Esta tecnología, llamada inyección intracitoplasmática de espermatozoides (ICSI), se aplica también a casos en los que el testículo posee sólo células inmaduras precursoras de espermatozoides, llamadas espermátidas.

A pesar de lo anterior, existen condiciones en que el testículo no produce espermatozoides. Es en estos casos donde se utiliza la donación del gameto masculino.

La donación de gametos femeninos u ovodonación se aplica en parejas heterosexuales en que la mujer no tiene ovarios. Por razones genéticas, quirúrgicas o por radioterápias en tratamientos de cáncer. También se aplica en mujeres con falla ovárica prematura, también llamada menopausia precoz. Ambas formas de donación están también indicadas cuando uno de los miembros de la pareja es portador de enfermedades ligadas a genes que, de ser transmitidos, ocasionarían enfermedades severas en la decendencia.

\section{Comentarios}

El hecho que maternidad, paternidad y familia pueden establecerse en ausencia de ligaduras genéticas está ampliamente demostrado con familias que se han constituido a través de la adopción de personas nacidas.

Los tratamientos médicos que utilizan la donación de gametos no son tratamientos de infertilidad. De hecho con estos tratamientos, no se logra que una mujer o un hombre que carece de gametos los tengan luego del tratamiento. Las terapias médicas en estos casos es- tán destinadas a hacer posible la maternidad y la paternidad en una pareja heterosexual. Complementario a ello, están destinados a hacer posible que el futuro hijo sea parido por quien ha expresado la voluntad de constituirse en su futura madre, independientemente de sus diferencias genéticas.

Progenitores son los individuos que aportan la información genética contenida en los gametos. La maternidad y la paternidad, por otra parte, no están necesariamente ligadas a la progenitura. Si así fuera, el amor maternal o paternal podría establecerse solamente con los niños que comparten una identidad genética directa, es decir, sólo con sus progenitores. Por otra parte, si el amor maternal o paternal se trasmitiese genéticamente, un progenitor estaría determinado irremediablemente a expresar amor paternal o maternal sólo para aquellos niños con los que está unido por la transferencia de sus genes. Como ambas situaciones no son reales, es razonable suponer que no existe un gen que transmita el amor maternal o paternal, y que el único puente capaz de establecer relaciones parenterales y de pertenencia como hijo está mediado por un puente de amor y por la voluntad de ser padre, madre e hijo.

La medicina reproductiva nos enseña que el útero de una mujer que carece de gametos, adecuadamente preparado, es más acogedor para recibir un conceptus con el que no comparte genes que con aquel que deriva de sus propios gametos. En general, las tasas de implantación (no de sacos gestacionales/no de concepti transferidos), que es una medida del nivel de receptividad del endometrio a un conceptus en desarrollo, son mayores en la fertilización in vitro con óvulos de donante que con los propios. De esta manera la naturaleza nos demuestra que nuestra biología está preparada para acogernos como hijos de una manera mucho más amplia que nuestro concepto de madre e hijo mediado exclusivamente a través de la genética.

Con frecuencia se habla de paternidad y maternidad biológica (para referirse a los que aportan los genes) y social (para referirse a los que se comportan como tales). Me parece que más acertado es referirse a progenitores en el primer caso y a padres y madres respecto de aquellos que asumen ese carácter social. Habitualmente, los progenitores y los padres son uno sólo, pero, como vimos antes, ambas situaciones pueden disociarse y la adopción de gametos representa, al igual que la adopción de un niño, un legítimo vínculo para establecer relaciones parenterales. 
Las tecnologías reproductivas modernas han puesto al hombre frente a una encrucijada de la que no parece tener escapatoria. O aprende de las enseñanzas de la naturaleza y develadas por la ciencia, o se cierra al conocimiento nuevo, sustentando su existencia sobre la base del inmobilismo y de los prejuicios. Cada vez que se mira con suficiente profundidad en la biología de la mujer, uno termina por convencerse que los conceptos de maternidad y familia a los que podemos acceder de acuerdo a nuestra naturaleza son infinitamente más amplios que aquellos que nuestra sociedad se ha impuesto. Estoy seguro que aquellos que se atrevan a aceptar los nuevos desafios científicos y reflexionen libremente sobre sus enseñanzas se verán enriquecidos al descubrir la amplitud con que la naturaleza nos acoge como una gran familia. El espíritu universal del Dios creador de todas las cosas precede al tiempo y es parte del tiempo. Existe desde antes de los orígenes del universo, ya que es su creador, y todo lo que de Él procede contiene una parte de su esencia originaria. Esa es el alma individual que es parte de toda materia como reflejo del creador. Es en esta perspectiva donde somos todos hermanos y es desde esta dimensión que la naturaleza nos acoge con amplitud y dulzura. Es evidente que lo que el hombre hace con su capacidad descubridora atenta muchas veces contra él mismo, sin embargo, la voluntad de saber más y el espíritu aventurero constituyen una fuerza que no puede ni debe detenerse por el miedo a lo desconocido, ya que esa aventura nos llevará irremediablemente al encuentro con el Creador.

Debemos ser pacientes para esperar que la sabiduría, que siempre llega, ayude a la humanidad a utilizar su inteligencia aprendiendo humildemente de la naturaleza que se le abre con el avance de la ciencia.

\section{Referência}

STEPTOE, P. C. \& EDWARDS, R. G., 1978. Birth after implantation of a human embryo. Lancet, 2: 366. 